\title{
A aprendizagem das diferenças sociais: classe, gênero e corpo em uma escola para meninas*
}

\author{
Graziela Serroni Perosa**
}

\begin{abstract}
Resumo
Este artigo discute a relação entre educação e estratificação social por meio do estudo de uma escola confessional feminina privada, voltada para atender famílias de alta renda na cidade de São Paulo, por volta de 1960. Interroga-se as modalidades de participação da escola na produção de disposições corporais $e$ habilidades sociais específicas, evidenciando-se de que maneira processos de escolarização podem estar na base da aprendizagem de diferenças de classe e gênero. Os procedimentos metodológicos incluíram questionários, entrevistas com ex-alunas, diretoras e exprofessoras, análise de fotografias dos ambientes e do cotidiano escolar. Os resultados sugerem que o exame das modalidades de escolarização é particularmente eficaz para a compreensão dos processos de diferenciação social nas sociedades contemporâneas.
\end{abstract}

Palavras-chave: Socialização, Escola Privada, Diferenciação Social.

\footnotetext{
* Recebido para publicação em março de 2006, aprovado em maio de 2006.

** Professora de Psicologia e Educação na Escola de Artes, Ciências e Humanidades (EACH) da Universidade de São Paulo. grazielaperosa@yahoo.com.br 
Classe, gênero e corpo em uma escola para meninas

Learning Social Differences:

Class, Gender and Body in a School for Girls

\begin{abstract}
This article discusses the relation between education and social stratification by means of a confessional private school for girls, targeting high-income families in the city of São Paulo circa 1960. The investigation focuses on the school's modalities of participation in the production of body dispositions and specific social skills, in an attempt to demonstrate how schooling methods may be the basis for learning class and gender differences. Methodological procedures included questionnaires, interviews with ex-students, principals and ex-teachers, and the analysis of photographs of the school's premises and routine. The results suggest that examining schooling modalities is particularly efficacious to the understanding of social differentiation processes in contemporary societies.
\end{abstract}

Key Words: Socialization, Private School, Social differentiation. 
Este artigo discute a relação entre educação e estratificação social por meio do estudo de uma escola confessional feminina privada, instalada na capital paulista em 1907, voltada para atender as famílias de grandes proprietários rurais e urbanos, profissionais liberais e altos funcionários do setor público $e$ privado. ${ }^{1}$ Interroga-se aqui as modalidades de participação da escola na produção de disposições corporais e habilidades sociais específicas, partindo do princípio de que a passagem pelo sistema de ensino, nas sociedades industrializadas, se tornou decisiva nos processos de diferenciação social. Os estudos que focalizam a relação entre escola e estrutura social evidenciam como a escola, além da instrução, está encarregada de inculcar valores e atitudes nos alunos responsáveis tanto pela formação de automatismos intelectuais de base, como pela construção da percepção que o indivíduo forma de si próprio na confrontação cotidiana com os outros. ${ }^{2}$ Aprende-se na escola uma concepção do masculino e do feminino que possibilita julgar natural que meninos e meninas desenvolvam determinadas competências, habilidades $e$ sensibilidades. Aprende-se também que ocupamos uma posição na hierarquia social, o que nos permite aceitar as diferenças sociais.

Sob o ponto de vista metodológico o texto apóia-se nos resultados de uma pesquisa empírica baseada em questionários,

1 A classificação ocupacional empregada a fim de considerar as atividades econômicas de pais e avós foi adaptada a partir do estudo de RIBEIRO, Luis César de Queiroz e LAGO, Luciana Corrêa. O espaço social das grandes metrópoles brasileiras: São Paulo, Rio de Janeiro e Belo Horizonte. Revista Brasileira de Estudos urbanos e regionais, n ${ }^{\circ} 3$, Recife, Associação Nacional de Estudos Urbanos e Regionais, 2000, pp.111-130. Considerou-se também na adaptação de uma classificação sócio-ocupacional para o grupo de famílias pesquisadas, o trabalho de PASTORE, José e SILVA, Nelson do Valle. Mobilidade Social no Brasil. São Paulo, Makron Books, 2000.

2 Ver, por exemplo, BouRdieu, Pierre. Systèmes d'enseignement et systèmes de pensée. Revue Internacionale des Sciences Sociales, 19 (3), 1967, pp.367-388; ver também, RINGER, Fritz Education and Society in Modern Europe. Bloomington/London, Indiana Universy Press, 1979. 
Classe, gênero e corpo em uma escola para meninas

entrevistas, observações de tipo etnográfico $e$ análise de documentos escolares, por meio dos quais foram identificadas as características sociais das famílias que recorriam à escola e a forma empregada pela instituição escolar para estruturar a socialização das meninas. Com base nesses resultados, a pesquisa interrogou os efeitos produzidos por esta socialização na trajetória familiar e profissional de um grupo de ex-alunas. ${ }^{3}$ Neste artigo abordamos o caso de um colégio de elite, o Colégio Des Oiseaux, visando a lançar luz sobre as modalidades de contribuição desta escola para a interiorização de um duplo pertencimento social, de classe e gênero.

A principal característica das famílias que procuravam esta escola, no período analisado, não residia simplesmente no fato de elas possuírem uma situação financeira privilegiada, capaz de arcar com as pesadas mensalidades impostas e habitar nos bairros chics da cidade. ${ }^{4} \mathrm{O}$ que as singularizava, em relação ao público de

3 A pesquisa empírica foi realizada, entre 2001 e 2004, com base em três escolas confessionais femininas privadas da cidade de São Paulo. Foram realizadas entrevistas aprofundadas com religiosas e diretoras das três escolas (7), com exprofessoras (6) e com ex-alunas da primeira geração do colégio (3), egressas entre 1920 e 1930. A partir da consulta ao arquivo das três escolas procurou se reconstituir os endereços atualizados de uma turma do secundário de cada escola, preferencialmente egressas em 1960 , período em que se intensifica o ingresso feminino no ensino superior brasileiro. Pelo Correio foram enviados 82 questionários para ex-alunas das três escolas, nos quais se solicitava um retorno reflexivo sobre as experiências educativas do grupo. Os questionários utilizados para produzir dados e informações comparáveis sobre três gerações de parte das famílias que recorriam a estas escolas. $\mathrm{O}$ tratamento destes dados foi realizado na École des Hautes Etudes em Sciences Sociales, sob a orientação de Salah Bouedja e Afrânio Garcia. Seguiram-se entrevistas biográficas (15) com exalunas das três escolas, nas quais explorou-se a história familiar e profissional das egressas das três instituições de ensino. A pesquisa incluiu ainda a análise das plantas escolares, das fotografias do ambiente e do cotidiano escolar, de boletins informativos produzidos pelas escolas e pela associação de ex-alunas do colégio Des Oiseaux. A pesquisa foi financiada pela FAPESP sob a orientação da Profa. Dra. Letícia Bicalho Canêdo, da Faculdade de Educação da Unicamp.

4 Parte dos dados aqui apresentados foram obtidos a partir da análise de 24 questionários respondidos por ex-alunas da escola que finalizaram o secundário 
outras escolas privadas da cidade, era o fato de que boa parte destas famílias estava nesta posição há pelo menos duas gerações. ${ }^{5}$ Ao comparar os recursos de duas gerações das famílias foi possível reconstruir empiricamente, e de maneira teoricamente sustentada, a composição desses patrimônios e dos recursos sociais responsáveis pela sua posição social.

Mais de dois terços das famílias pesquisadas eram chefiadas por grandes proprietários rurais e urbanos, altos funcionários públicos e privados e profissionais liberais empregadores; profissionais empregados de nível superior $e$ pequenos comerciantes não chegavam a representar $10 \%$ das famílias. ${ }^{6} \mathrm{Na}$ geração dos avós, metade das famílias estudadas estava ligada à terra, possivelmente herdeira dos proprietários de escravos do século XIX, mas que já expandira seus negócios para a cidade de São Paulo. ${ }^{7}$ Elas possuíam uma riqueza variada $e$ multidimensional, que, longe de se restringir à abundância de recursos financeiros, converteu-se progressivamente em prestígio $e$ na composição de uma rede durável de relações sociais, mais

por volta de 1960. Nesta ocasião o número total de alunas da escola, incluindo primário, ginásio e secundário, estava em torno de 600 alunas. Fonte: Entrevista de Pesquisa com a Madre Superiora do período em questão. São Paulo, 6/2/2001.

5 "Advogado, político, vereador, fazendeiro cafeicultor, desbravador". Assim uma ex-aluna do colégio descreveu a atividade econômica de seu avô materno, paulista, nascido em 1879. Dois terços dos avós da ex-alunas consideradas na pesquisa possuíam um diploma do ensino superior, muito freqüentemente obtido na Faculdade de Direito do Largo de São Francisco. O questionário que produziu esses dados encontra-se apresentado na íntegra em PEROSA, Graziela Serroni. Três escolas para meninas. Tese de Doutorado, Faculdade de Educação/Unicamp, 2005.

${ }^{6}$ A sub-categoria "empregados de nível superior" na classificação desenvolvida por Ribeiro permite distinguir os profissionais de nível superior autônomos $e$ empregadores dos assalariados. Cf. RIBEIRO, L. C. Q. e LAGO, L. C. O espaço social das grandes metrópoles brasileiras... Op. cit., p.114.

7 Aproveitando a diversificação da atividade industrial e comercial em ascensão desde as primeiras décadas do século XX. Cf. CANO, Wilson. Raízes da concentração industrial em São Paulo. São Paulo, Difel, 1977. 
Classe, gênero e corpo em uma escola para meninas

ou menos institucionalizadas de interconhecimento, fundando os sentimentos de pertencimento a um grupo. ${ }^{8}$ Mais precisamente, metade das ex-alunas consideradas neste estudo possuía pai ou algum avô ocupando cargos políticos de nível estadual ou federal ou engajados na direção de associações de classe, dentre as quais, destaca-se o Instituto Brasileiro de Café (IBC) ou a Federação das Indústrias do Estado de São Paulo (FIESP) ${ }^{9}$, "gente que o próprio nome já apresentava a pessoa...", na definição da madre superiora referindo-se às famílias de suas alunas. ${ }^{10}$ Estas famílias acumulavam diversas fontes de renda, articulando a posse de grandes extensões territoriais com a ocupação de cargos eletivos, de indústrias e instituições financeiras, e o exercício de profissões liberais e cujo prestígio, não raro, estava expresso em um sobrenome conhecido. ${ }^{11}$

Um terço destas famílias possuía entre seis e dez filhos e a maioria delas habitava em residências amplas ${ }^{12}$, dispondo de pelo menos três empregados domésticos que trabalhavam uniformizados e residiam ali. Elas habitavam os bairros chics da cidade - Higienópolis, Jardim Europa, Jardim América, Jardim Paulistano e Jardim Paulista ${ }^{13}$-, lugares procurados pelas famílias

8 Cf. Bourdieu, P. Le capital social - notes provisoires. Actes de la recherché en sciences socials, $\mathrm{n}^{\circ}$ 31, Paris, 1980, pp.2-3.

9 Fonte: Dados obtidos com os questionários.

${ }^{10}$ Fonte: Entrevista de pesquisa, São Paulo, 10/5/2002.

${ }^{11}$ Um caso emblemático das estratégias de reprodução social das antigas famílias ricas paulistas pode ser notado pela história da família Prado. A posse de grandes extensões de terra, a comercialização lucrativa do café na virada do século e as alianças matrimoniais com famílias conhecidas lhes permitiram criar instituições financeiras, ocupar posições estratégicas na Companhia Paulista de Estradas de Ferro e cargos políticos de primeiro escalão na província de São Paulo. Cf. LEvi, Darrel. A família Prado. São Paulo, Cultura 70, 1977.

${ }^{12}$ Metade destas famílias (12) residia em casas que possuíam entre 300 e 700 $\mathrm{m} 2$, quatro delas em casas que tinham entre 700 e $1000 \mathrm{~m} 2$ e apenas duas em casas com até $200 \mathrm{~m} 2$. Fonte: Questionários aplicados para a pesquisa.

${ }^{13}$ Vinte sobre vinte e quatro das famílias consideradas aqui residiam nestes bairros. Fonte: Questionários aplicados para a pesquisa. 
abastadas e comercializados como redutos de tranqüilidade, conforto $e$ boa vizinhança, naturalmente com altos valores imobiliários. ${ }^{14}$ Com ruas largas, repletas de áreas verdes, estes bairros se transformaram em "grifes espaciais", reputação estreitamente ligada às propriedades sociais dos seus habitantes. ${ }^{15}$ Nos bairros nobres, como se diz freqüentemente, nas grandes residências garantia-se uma relação com o espaço no qual as crianças aprendiam cedo a usufruir de um espaço amplo e seguro. Nessas situações, em tudo oposta à condição das crianças que vivem em espaços menores/exíguos, dispõe-se sempre de lugar para si e a dificuldade consiste em administrar o corpo $e$ a apresentação de si no meio circundante. ${ }^{16}$

As relações de proximidade entre estas famílias se estendiam também pela freqüência aos mesmos clubes esportivos, antigos redutos de lazer das famílias ricas da cidade tais como o Jockey Club de São Paulo (1875), o Clube Athlético Paulistano (1900) e a Sociedade Harmonia de Tênis (1930). ${ }^{17}$ Para essa sociabilidade,

${ }^{14}$ Cf. REALE, Ebe. Brás, Pinheiros e Jardins: três bairros, três mundos. São Paulo, Editora da USP, 1973; ver também, MARINS, Paulo César Garcez. Habitação e vizinhança. In: SEVCENCKO, Nicolau. História da vida privada no Brasil. São Paulo, Companhia das Letras, 1988.

${ }^{15}$ Sobre a transformação de espaços urbanos das grandes metrópoles em "griffes espaciais", consultar, PINÇON, Michel e PINÇON-CHARLOT, Monique. Dans les beaux quartiers. Paris, Le Seuil, 1989; ver também, PINÇON, M. e PINÇONCHARLOT, M. Grandes fortunes: dynasties familiales et formes de richesse en France. Paris, Payot, 1998; sobre a concentração espacial de famílias de alta renda nas metrópoles brasileiras, consultar, VILLAÇA, Flávio. Espaço intra-urbano no Brasil. São Paulo, Fapesp, 1998, p.192.

${ }^{16}$ Cf. PInçOn, M. e PInçOn-Charlot, M. Sociologie de la bourgeoisie. Paris, La decouverte, 2000, p.55.

${ }^{17}$ O Jockey Club de São Paulo foi fundado por um grupo de amigos de famílias antigas e bem estabelecidas na cidade: Eleutèrio Prado, José de Souza Queiroz, Rafael de Barros, entre outros e tornou-se um centro de entretenimento para apreciadores de cavalos puro sangue inglês. Da mesma maneira, o Paulistano foi fundado como um clube de esportes por Horácio Spíndola, Bento Bueno, Sampaio Viana e vários outros membros da família Silva Prado, Antonio Prado Jr., Plínio da Silva Prado e Martinho Prado. O clube "Harmonia" foi fundado 
Classe, gênero e corpo em uma escola para meninas

gerida fundamentalmente pelas famílias, as escolas privadas vinham a calhar com sua promessa de homogeneidade de público, com qualidades estéticas na arquitetura e na atmosfera da escola semelhante àquelas encontradas em casa, nas ruas destes bairros, nos clubes, resultando em uma socialização extremamente controlada, muito diferente da maior parte das crianças entre as quais as instâncias de socialização não oferecem a mesma coerência.

Por meio desta escola confessional, estas famílias mantiveram o controle sobre as redes de convivência de suas crianças em um período de acentuada expansão do sistema público de ensino e da progressiva transformação da clientela destes estabelecimentos de ensino. Some-se a isto o fato de que os colégios católicos fossem percebidos como o espaço por excelência de formação dos grupos de elite no Brasil, desde o período colonial. Matricular as meninas em um estabelecimento de ensino católico e particularmente renomado na cidade, como o Colégio Des Oiseaux, representava, portanto, uma dupla operação de agregação e segregação social, pois mantinha a distância espacial e social dos grupos populares e inseria suas meninas na rede de relações das famílias conhecidas. O alto grau de endogamia examinado no grupo pesquisado é um dos principais indícios do êxito do controle destas famílias, realizado por meio da escola, visando a manter, ampliar ou transmitir sua posição social à geração seguinte. A partir das experiências educativas vividas no interior desta escola as jovens e as crianças aprendiam a viver em conjunto, a se conhecer e a se reconhecer como "iguais".

A opção pela escola católica significou ainda garantir a familiarização precoce e intensiva das meninas com a moral católica que celebra o eterno retorno da mulher à casa $e$ aos

como resultado da ação de um grupo de sócios do Paulistano aficionados por tênis. Fonte: FERnANDES, Paula Porta. (org.) Guia dos Documentos Históricos na Cidade de São Paulo, 1554/1954. São Paulo, Editora Hucitec/NEPS, 1998, pp.605-630 
cuidados da família em um contexto social de acentuadas modificações econômicas, sociais e culturais, em especial, no que diz respeito à "condição" feminina. ${ }^{18}$ Nas escolas confessionais femininas o acento da experiência escolar era moral - o controle emocional, a apresentação de si, a dedicação, a modéstia ${ }^{19}-e$ o programa escolar privilegiava a aquisição de uma formação estética e literária. Assim, os colégios católicos representavam uma alternativa para garantir a instrução feminina, sem abrir mão de uma socialização cujo acento fosse moral $e$ não profissional. Estava em curso um programa de aprendizagem das diferenças sociais - de classe e gênero - que traduzia as lutas dos grupos familiares para controlar a educação escolar das meninas de forma a ajustá-las às suas estratégias de reprodução social. Tratava-se, mais precisamente, de adquirir as disposições necessárias para ocupar uma posição dominada, no interior de um grupo socialmente dominante.

\section{Uma escola para meninas}

A chegada das congregações religiosas no Brasil se intensificou no início do século XX, como resultado da institucionalização da escola republicana na Europa $e$ do conseqüente fechamento das escolas confessionais na maioria dos países europeus ocidentais. A reação das instâncias decisórias na Igreja Católica resultou em uma série de iniciativas que teriam como finalidade o fortalecimento organizacional da instituição $e$ as condições mínimas de sobrevivência política e material das

\footnotetext{
${ }^{18}$ Durante uma longa entrevista a professora de filosofia da escola lembrou-se da discussão das alunas sobre "se a mulher deveria trabalhar ou não trabalhar depois da faculdade", por ocasião de um retiro espiritual promovido pela escola em Campos de Jordão. No dormitório, repleto de beliches "houve uma discussão enorme, onde a M... defendia que a mulher deveria ter a sua profissão independente do seu marido". Fonte: Entrevista de pesquisa, 8/7/2002.

19 "Je suis modèste et soumise" era uma das orações do exercício de francês de uma escola católica da cidade nos idos de 1930. Fonte: Entrevista de pesquisa. São Paulo, novembro de 2001.
} 
Classe, gênero e corpo em uma escola para meninas

diversas ordens religiosas criadas no final do século XIX. A vinda para a América Latina e a abertura de escolas privadas foi uma das formas encontradas pela Igreja Católica de realizar seu projeto de expansão patrimonial. ${ }^{20}$ No Brasil, com o fim do padroado e o início do período republicano, as congregações desembaraçaram em um espaço social livre do arbítrio da monarquia. Neste contexto, as Irmãs de Nossa Senhora das Cônegas de Santo Agostinho vindas da Bélgica chegaram à São Paulo em 1906 e fundaram o Colégio Nossa Senhora das Cônegas de Santo Agostinho, em 1907. ${ }^{21}$ Por intermédio do apoio dos beneditinos do Ginásio de São Bento, da capital paulista, instalaram-se provisoriamente na Avenida Paulista, a esta época já ocupada pelos casarões que abrigavam imigrantes. ${ }^{22}$ Para criar o colégio, adquiriram um palacete localizado no bairro da Consolação, nas imediações de Higienópolis.

A aquisição do belo palacete correspondia às intenções da ordem de estabelecer-se como opção de educação católica para meninas das famílias abastadas. Sua arquitetura de inspiração art nouveau emprestava um ar requintado ao novo colégio que iniciou suas atividades em 1907, com um jardim de infância misto, primário e ginasial feminino, em regime de internato, modalidade preferida por fazendeiros que residiam nas fazendas e também por aqueles que estavam se estabelecendo na capital. Lançaram ainda o regime de semi-internato para atender a uma clientela urbana que crescia á olhos vistos. Os amplos jardins, frontais e laterais do edifício garantiam a distância espacial conveniente da rua, à semelhança do que ocorria com as habitações das camadas de

${ }^{20}$ Cf. MiCELI, Sergio. A elite eclesiástica brasileira. Rio de Janeiro, Bertrand Brasil, 1988, p.12.

${ }^{21}$ Ainda na Bélgica, as irmãs agostinianas teriam sido convidadas pelo abade à frente do principal colégio católico masculino no Rio de Janeiro, Dom Van Caloen, do Mosteiro de São Bento. Fonte: "A primeira fundação brasileira: mosteiro-colégio das Cônegas de Santo Agostinho". In: Passos da Nossa História, $n^{\circ}$ 3, São Paulo, Vicariato do Brasil, 1998, pp.1-50.

${ }^{22}$ Cf. MARINS, P. C. G. Habitação e vizinhança. Op. cit., pp.131-214. 
alta renda instaladas nesta parte da cidade. A extensão desses jardins permitia a entrada de automóveis transportando as alunas, transformando as saídas do colégio em um espetáculo para ser visto à distância pelos transeuntes do bairro, "as saídas do colégio eram famosas", relatou uma ex-aluna do colégio. ${ }^{23}$ Nessas ocasiões, as meninas posicionadas na escadaria da entrada principal pareciam constituir um mundo à parte com seus uniformes, o luxo dos automóveis e seus chauffeurs. Vale sublinhar, o edifício dos colégios católicos de elite distinguiam-se dos prédios escolares públicos construídos no início da República, cujas escadarias $e$ fachadas normalmente não tinham recuo da calçada. ${ }^{24}$

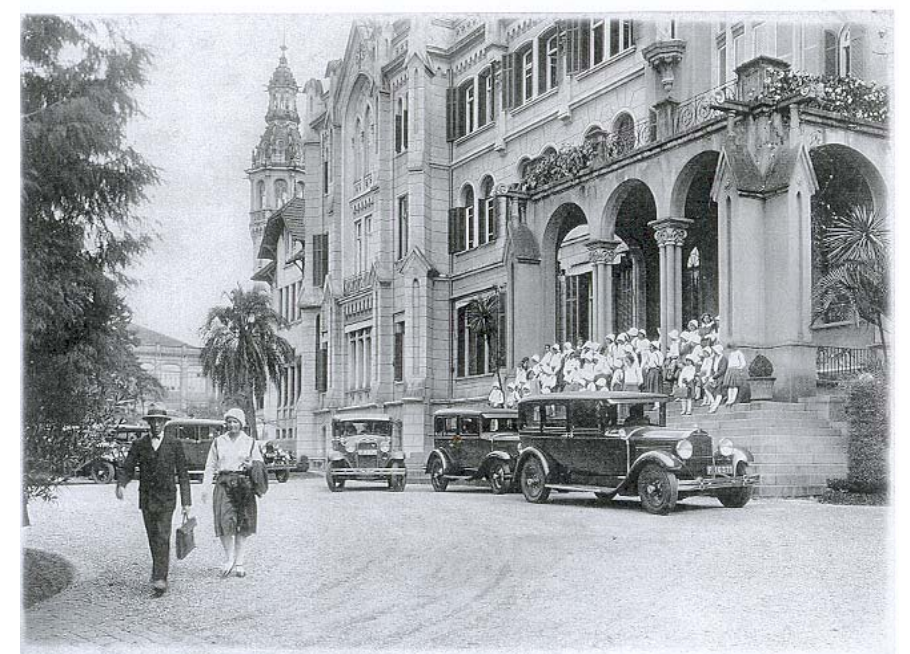

Fotografia 1: Colégio Des Oiseaux, por volta de 1920.

Vê-se à esquerda a torre do Palacete Uchoa.

Fonte: Arquivo Pessoal de Irmã M. D.

${ }^{23}$ Fonte: Entrevista de Pesquisa com uma ex-aluna do Des Oiseaux por volta de 1930, realizada em 19/06/2002.

${ }^{24}$ Cf. Buffa, Éster \& PINTO, Gerson de Almeida. Arquitetura e educação. São Carlos, Edufscar/INEP, 2002. 
Classe, gênero e corpo em uma escola para meninas

Como desde 1901 já funcionava o Colégio Nossa Sra do Sion, localizado na principal avenida do bairro de Higienópolis, as agostinianas lançaram-se nesse espaço social mobilizando trunfos fortes. Além da localização privilegiada, as irmãs investiram na identificação desta escola como um autêntico colégio francês. Nomeado inicialmente como Collège des Dames de St. Augustin, as irmãs o apresentaram como uma filial do Colégio Notre-Dame Des Oiseaux de Paris, que atendia as famílias da antiga nobreza francesa e da grande burguesia parisiense. ${ }^{25}$ Se considerarmos que as aulas eram em francês até meados de 1930, o hábito das religiosas belgas no Brasil era o mesmo das francesas $e$, mais tarde, o uniforme das alunas também se assemelhava ao do colégio francês, não é difícil compreender o êxito da associação entre os dois estabelecimentos de ensino e porque este colégio de freiras paulistano tornou-se conhecido simplesmente como colégio Des Oiseaux.

\section{Um prolongamento da família}

Boa parte das irmãs responsáveis pelo Colégio Des Oiseaux provinha de famílias antigas e bem estabelecidas na sociedade paulista. ${ }^{26} \mathrm{O}$ recrutamento tanto das religiosas da congregação,

25 "De Jupille, Madre Teresa da Cruz, que havia estudado no Colégio 'Des Oiseaux' de Paris, escrevera a diversas senhoras brasileiras, suas colegas no colégio francês, recomendando as Irmãs que acabavam de chegar a São Paulo. A recepção foi calorosa! Reconhecendo o hábito das antigas mestras, as ex-alunas exclamaram: são nossas mestras do Des Oiseaux! Que felicidade tê-las em São Paulo". Pela lista das primeiras alunas do colégio nota-se o êxito das irmãs no recrutamento deste público: Camila de Souza Queiroz, Judth Guedes, Marina Prado Penteado, Alba de Salles Oliveira, Jandyra de Campos, Sarah Mesquita, Maria Prado Guimarães, entre outras. Fonte: Passos da Nossa História. Op. cit., p.10.

${ }^{26}$ Dentre elas, Almeida Prado, Pereira Leite, Salles de Oliveira, Sodré Dória, Sampaio Bueno, etc. Fonte: LIMONGI, Maria Evangelina (Irmã). A primeira fundação brasileira: colégio-mosteiro de São Paulo, 1906. Passos da Nossa História. Op. cit., p.17. Sobre as irmãs européias, os dados obtidos foram mais esparsos e menos conclusivos, a julgar pelos depoimentos, tratava se uma origem 
como de professoras tendia a ocorrer preferencialmente entre exalunas, não raro, filhas de ex-alunas do colégio. Elas possuíam, portanto, uma experiência educacional muito semelhante àquela que estavam incumbidas de manter neste estabelecimento de ensino, tornando ainda mais efetiva a chance de êxito na transmissão dos valores pretendidos. ${ }^{27}$ Famílias e religiosas partilhavam a mesma concepção do papel da escola e da família na educação das meninas.

De certa maneira, o colégio tendia apenas a dar continuidade à educação recebida no meio familiar, sem jamais contrariá-la, à semelhança do que descreveu Monique de Saint Martin sobre Colégio Notre Dame Des Oiseaux de Paris. ${ }^{28}$ Muitas alunas e irmãs pertenciam ao universo social das grandes famílias, residentes já há algumas gerações em São Paulo, por vezes, ligadas entre si por relações de parentesco, alianças políticas $e$ antigas solidariedades reforçadas pela freqüência aos mesmos estabelecimentos de ensino. Isso garantia que as irmãs se dirigissem, com seu programa educacional, a um público previamente convertido de sua legitimidade, favorecendo um clima de confiança entre as famílias e o colégio. Não por acaso, quando interrogadas sobre o que mais gostavam em seu colégio, dezoito das vinte e quatro alunas consideradas, assinalaram "a atmosfera da escola" entre suas preferências. Por outro lado, quando indagadas sobre se havia algo em sua experiência escolar que lhe fizesse sofrer, metade do grupo registrou categoricamente "não me lembro de sofrer no colégio". As razões apontadas pela outra metade que declarou sofrer no colégio variaram bastante, indo desde "o sistema de premiação das melhores alunas", "a

social elevada, "eu sei que tinha uma que diziam ser de uma família da nobreza inglesa", contou-nos uma ex-aluna. Fonte: Entrevista de pesquisa, São Paulo, março de 2003.

${ }^{27}$ Das cinco irmãs e ex-professoras entrevistadas durante a pesquisa, três delas são ex-alunas do Colégio Des Oiseaux e filhas de ex-alunas do colégio.

${ }^{28}$ Cf. SaInT Martin, Monique de. Une "bonne" éducation: les oiseaux, à Sèvres. Ethnologie française, vol. 20, 1990, pp.60-70. 
Classe, gênero e corpo em uma escola para meninas

disciplina", "o esporte e as atividades não escolares", "o programa de ensino", o "momento das refeições", entre outros, exigindo para sua compreensão uma análise mais fina da posição de cada uma das meninas no interior do colégio. ${ }^{29} \mathrm{~A}$ cena preparada para a fotografia 2 , na qual uma irmã parece orientar suavemente uma aluna sorridente, expressava bem a imagem da educação pretendida pelo Des Oiseaux: suave e controlada $^{30}$, factível $e$ possível graças à proximidade na origem social de religiosas $e$ alunas o que permitia ao colégio prolongar e completar a educação familiar, sem jamais contrariá-la.

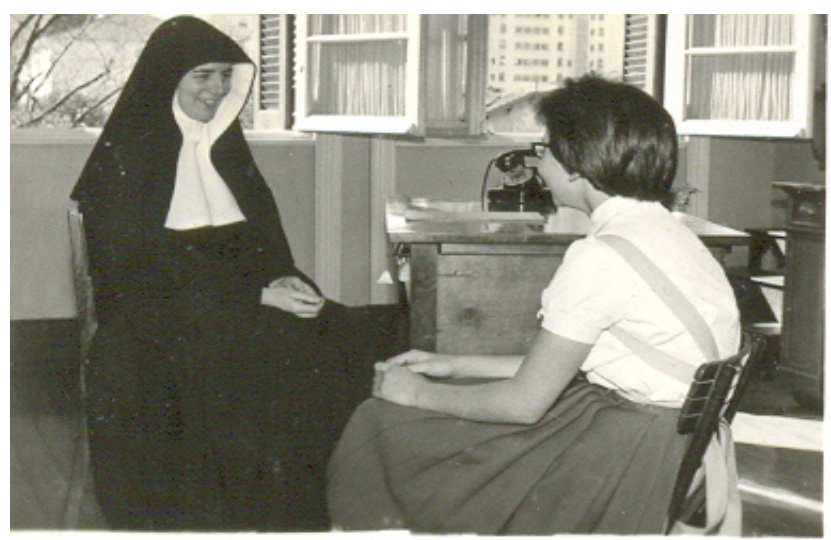

Fotografia 2: Irmã e aluna do Des Oiseaux, em 1958.

Fonte: Arquivo pessoal da Irmã M. E.

\footnotetext{
${ }^{29} \mathrm{Na}$ íntegra as duas questões elaboradas sobre a relação das meninas com a escola: "o que você mais gostava no seu colégio?" e "lembra-se de algo na sua experiência escolar que lhe fazia sofrer?". Fonte: Questionários aplicados para a pesquisa. Ver, PEROSA, G. S. Três escolas para meninas. Op. cit., p.172.

${ }^{30}$ No relato de uma ex-aluna que migrou do Des Oiseaux para o Santa Maria na tentativa de sintetizar o espírito do colégio "elas falavam mansinho e te botavam de castigo...". Fonte: Entrevista de Pesquisa, fevereiro de 2004.
} 
O controle do público atendido pelo colégio não se restringia apenas a uma segregação de base financeira realizada, ademais, por qualquer escola privada. Nesse caso, havia critérios que regravam a admissão e a expulsão da escola direcionando ainda mais o recrutamento social da clientela e terminaram por garantir um público ainda mais homogêneo para o colégio. Ser batizada na Igreja Católica era, evidentemente, uma exigência mínima e comum à boa parte das escolas católicas da cidade. No Des Oiseaux, o ingresso estava absolutamente garantido às filhas e netas de ex-alunas e vedado, por exemplo, às "filhas de pais divorciados", um estigma forte no período que destoava da imagem que se pretendia, de uma escola voltada para moças de "boa família". Esses mecanismos de seleção das alunas eram mobilizados porque preservavam e promoviam a reputação da escola, não raro, associada à "qualidade" do público que a instituição atende. É certo que tratava se de atrair uma clientela em meio a um espaço escolar altamente diversificado e a um mercado escolar competitivo, se consideramos que, por volta de 1950, São Paulo já abrigava 60 estabelecimentos de ensino católicos instalados nos principais bairros da cidade, com pelo menos um terço dedicado exclusivamente à educação feminina. ${ }^{31}$

\section{A escola e a interiorização do pertencimento social}

Como bem descreveu Mary Mc Carthy no interior dos colégios católicos, no silêncio de seus corredores, uma rede de sociabilidade densa e tensa era tecida entre alunas e na relação com as religiosas. ${ }^{32}$ As rivalidades, concorrências e lealdades tomavam forma nesse universo, onde todos controlavam todos: as medalhas ao mérito, ao bom comportamento e à obediência total às regras locais costumavam ser solenemente aplaudidas. Não

${ }^{31}$ Cf. Perosa, G. S. Três escolas para meninas. Op. cit., p.37.

${ }^{32}$ Cf. Mc CARTHY, Mary. Memórias de uma menina católica. São Paulo, Círculo do Livro, 1957. 
Classe, gênero e corpo em uma escola para meninas

falar, não cantar e não rir alto, parecer sempre no tom certo $e$ não destoar do conjunto ${ }^{33}$, comportamentos exigidos e premiados nas diversas situações de aprendizagem tanto dos saberes escolares, como nas ocasiões em que estava em jogo a aquisição de um certo savoir-vivre - saber se vestir, saber comer, falar francês, dominar a arte de conversar ${ }^{34} e$ as técnicas de controle do corpo que produzem uma aparência de dignidade e nobreza - a boa aparência - qualidades úteis em diversas cerimônias sociais que compõem o estilo de vida neste grupo social.

Isso não quer dizer que as irmãs relegassem a um segundo plano a aquisição do saber escolar. Ao contrário, orgulhavam-se de contratar bons professores, de investir na formação prolongada das irmãs e de contar entre os professores homens da escola com autores de livros de suas respectivas disciplinas ${ }^{35}$, engajados, muitas vezes, em operar um currículo "experimental" pontuado por concessões pedagógicas em relação aos métodos tradicionais de ensino. Enquanto em outras escolas católicas mais austeras, a aprendizagem da disciplina de História, por exemplo, estava organizada a partir de trabalhos escolares baseados nas datas comemorativas dos acontecimentos cívicos, no Des Oiseaux a

\footnotetext{
${ }^{33}$ Não sem tristeza, uma ex-aluna de uma das escolas pesquisadas lembrou-se de sua experiência no coral de sua escola. As irmãs alegando que ela fosse "desafinada" sugeriram que ela permanecesse no coral, mas fazendo apenas os movimentos labiais. Fonte: Entrevista de pesquisa, São Paulo, fevereiro de 2003.

${ }^{34} \mathrm{O}$ aprendizado desta habilidade incluía naturalmente a aquisição da polidez, mas possuía também conteúdos significativos "não falar da vida pessoal", por exemplo. Regra cuja incorporação está na base de alguns automatismos notados no grupo por ocasião das entrevistas. Em comparação com as demais escolas estudadas, as egressas do Des Oiseaux foram mais sóbrias, mais discretas na interação com a pesquisadora, basicamente controlando o interesse pela pesquisa, jamais demonstrando, em um primeiro momento, um entusiasmo presente entre ex-alunas das outras escolas. Mesmo que este interesse tenha se revelado na disponibilidade de responder os questionários e em conceder as entrevistas, mas sua expressão foi sempre acompanhada de muita discrição.

${ }^{35}$ Aroldo de Azevedo, autor de diversos livros em sua área, lecionou Geografia no colégio durante muitos anos. Fonte: Entrevista de Pesquisa, junho de 2002.
} 
professora de História (ex-aluna e filha de ex-aluna da escola) relatou como desenvolvera um "método experimental" de ensino de sua disciplina. Para exemplificá-lo, contou que pedia às meninas para elaborar "uma linha do tempo" e solicitava que as alunas relacionassem $\mathrm{o}$ nascimento de seus antecedentes familiares aos principais acontecimentos da história recente brasileira. Estratégias pedagógicas como esta caracterizam-se por apresentar o trabalho escolar como produção e não como reprodução de um conhecimento ao qual é preciso submeter-se, esforçando-se para memorizá-lo. ${ }^{36}$ Mas ao lado do programa de estudos implementado pelo colégio havia toda uma dimensão socializadora presente nas solenidades escolares, no momento das refeições e no emprego dos uniformes. Esses momentos compunham parte importante dessa experiência educativa $e$ intimamente relacionada à elaboração de uma representação de si e da construção de uma maneira de se apresentar aos outros.

Para as famílias que buscavam tais estabelecimentos de ensino, parte importante da educação dizia respeito à aprendizagem de uma maneira de ser. Se para a classe média e para a burguesia em ascensão tratava-se de adquirir, por exemplo, etiqueta à mesa, a antiga elite visava à construção de afinidades entre "iguais". "As meninas do Des Oiseaux sabiam comer", declarou uma antiga professora. "Saber comer" é um desses sinais de distinção social que funcionam como um atestado simbólico da suposta superioridade de alguém em relação aos outros, revelando seu grau de familiaridade com a cultura, de antiguidade neste meio social, bem como seu distanciamento da natureza. "Saber comer" poderia, em diversas situações, dar provas do lugar ocupado no mundo social. Daí a importância reservada pela escola ao momento das refeições. Por meio da aquisição de determinados hábitos à mesa fundavam-se critérios de julgamento

${ }^{36}$ Cf. AlmeidA, Ana Maria. Língua Nacional, competência escolar e posição social. In. ALmEIDA et alli. Op. cit, 2004, p.40. 
Classe, gênero e corpo em uma escola para meninas

sobre as diferenças sociais e mais especificamente, sobre uma posição social em relação às outras. ${ }^{37}$

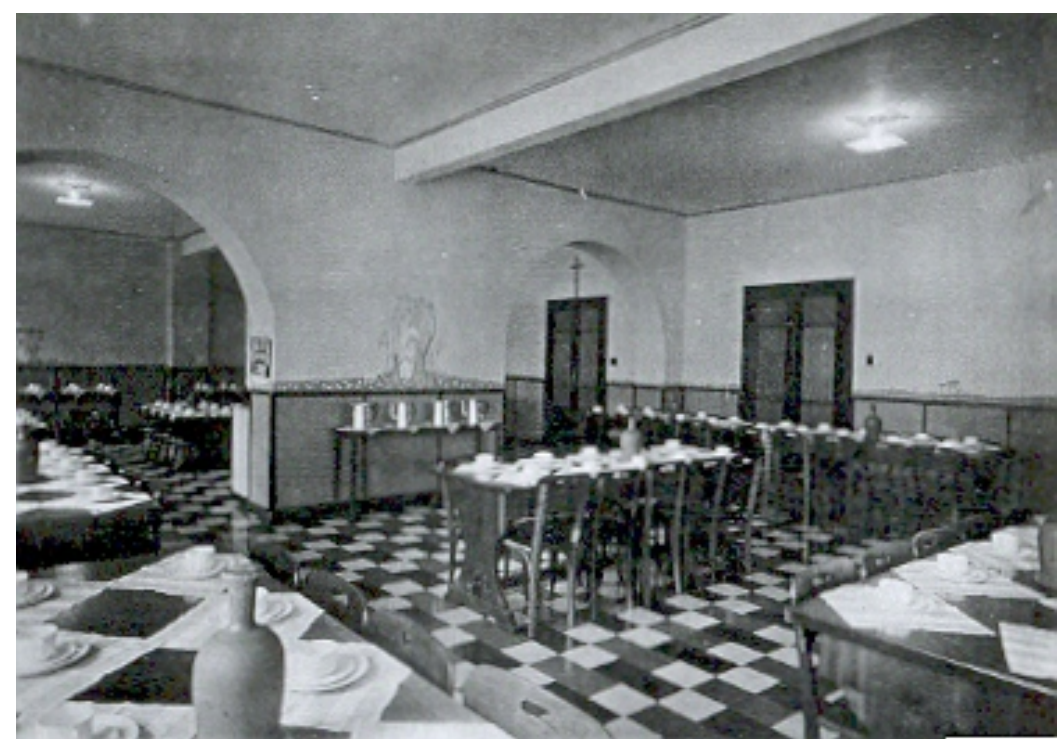

Fotografia 3: Refeitório do Des Oiseaux.

Fonte: Arquivo pessoal de Irmã M.D. Sem data.

A aprendizagem dos códigos de "boa conduta" está relacionada às modificações de comportamentos mais permanentes, aqueles que, incorporados, torna-se quase uma segunda pele. Saber controlar o corpo no momento das refeições significava dispor de um poder importante sobre si mesmo, um controle social amplamente aceito, aprovado e valorizado. No colégio Des Oiseaux, esse momento assumia a forma de uma verdadeira cerimônia. "As freiras comandavam tudo fazendo um pequeno 'clac' com um livro de madeira", descreveu uma ex-

${ }^{37}$ Como bem demonstrou Norbert Elias, a etiqueta à mesa se constituiu na sociedade de corte francesa e foi utilizada como uma arma da nobreza diante do seu declínio contra a burguesia ascendente do século XIX. Cf. ELIAS, Norbert. La société de cour. Paris, Champs Flammarion, 1985, p.94. 
aluna. As meninas entravam silenciosamente em fila, sentavam-se nos lugares marcados, pegavam os talheres de prata trazidos de casa com o nome de família gravado e acompanhados da argola do guardanapo. "Alguém nos servia", conta a mesma ex-aluna. A refeição era um momento ritualizado, com duração e ritmo bem determinados, no qual a língua obrigatória era o francês e não português. ${ }^{38} \mathrm{O}$ controle de regras de etiqueta não era realizado diretamente pelas irmãs, mas sim pelas meninas umas em relação às outras: "pegaria mal você comer feio", declarou uma ex-aluna. Tudo funcionava como se não fosse preciso impor as regras de etiqueta, pois, as meninas as trariam de casa. Tratava-se de treinar a naturalidade com este código, cuja aplicação desenvolta era controlada no interior do grupo. Essa forma de estruturar a aprendizagem social torna seu caráter coercitivo quase imperceptível e, por isso mesmo, ainda mais eficaz, pois associada à sua aceitação no grupo e não à obediência a uma autoridade externa.

Saber vestir-se e controlar a exposição do corpo era outra dimensão importante desta socialização escolar. Ao observar as práticas de gestão dos uniformes escolares, nota-se que vestindose as meninas expressavam sua posição social, tornavam-se pouco a pouco conscientes dela e construíam progressivamente uma imagem sobre si mesmas. Por meio dessa experiência educativa reforçava-se uma determinada concepção sobre o papel feminino na composição do seu grupo social. Isso pode ser percebido comparando-se fotografias e depoimentos de ex-alunas sobre os uniformes no Colégio Des Oiseaux.

\footnotetext{
${ }^{38} \mathrm{O}$ francês era utilizado pelas religiosas entre si e era proibido que elas se comunicassem em português. Entre as alunas a mesma regra valeu até antes dos anos de 1930. Depois disso, com a obrigatoriedade de que todas as escolas ministrassem os cursos em português, o francês passou a ser empregado durante as refeições e durante a prática de esportes. Fonte: Entrevistas de pesquisa com ex-alunas e religiosas.
} 
Classe, gênero e corpo em uma escola para meninas

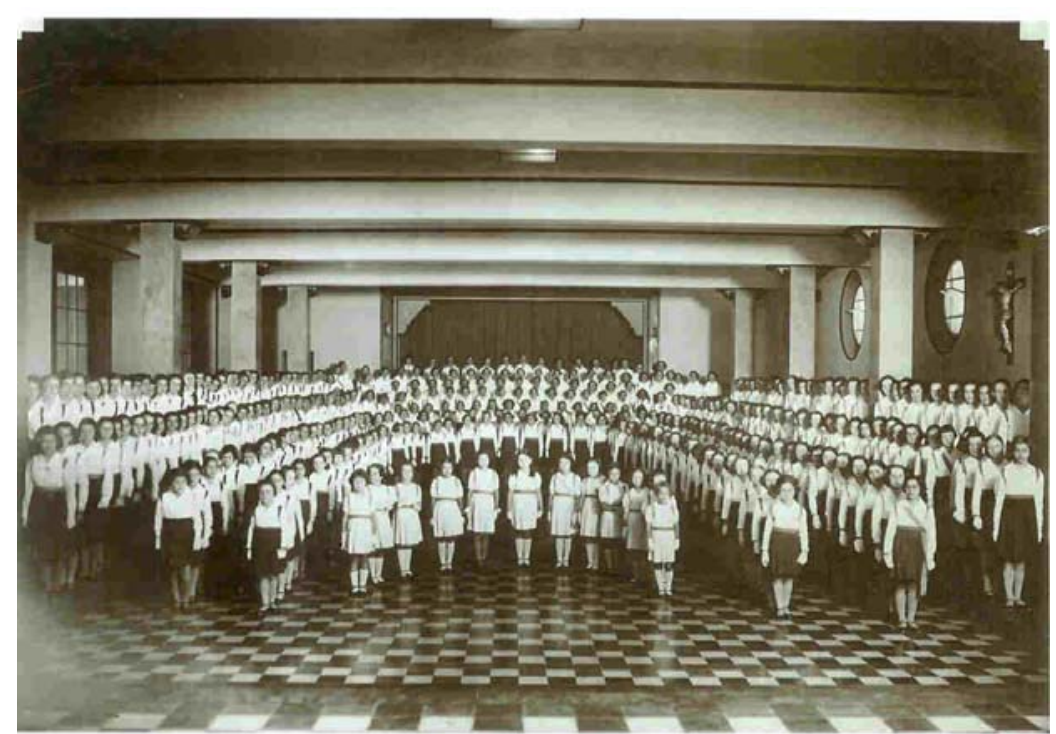

Fotografia 4: Conjunto de alunas do colégio Des Oiseaux, reunidas para uma cerimônia no salão de festas da escola, entre 1940 e 1950. Fonte: Arquivo pessoal da Irmã M. D.

"Era tudo muito solene, filas por tamanho, as meninas não podiam sair sem luvas diariamente até 1953, 1954", lembrou uma antiga madre superiora da escola. O retrato acima sugere uma atmosfera na qual se respirava a ordem, a disciplina e o respeito à hierarquia natural dos corpos (baseada aqui na idade e no tamanho), critérios que estruturavam a disposição das meninas no salão. "O uniforme do Des Oiseaux era um cartão de visitas, eu gostava de vesti-lo, tinha orgulho de ser amarela, azul', informou uma ex-aluna, fazendo referência às fitas de cetim que sinalizavam a progressão na seriação escolar. Parte do brilho dos rituais religiosos e das cerimônias escolares nessa escola dependiam do cuidado com os uniformes. As entradas e saídas do colégio com as meninas vestidas com luvas e chapéu, na escadaria do belo 
edifício, transmitiam a imagem pretendida de homogeneidade social, luxo e distinção. As clássicas saias plissadas eram acompanhadas de meias três quartos, ponto de honra nos colégios católicos femininos, visto que as pernas estavam fortemente relacionadas à sensualidade feminina.

Em muitas outras escolas privadas os uniformes estavam encarregados de produzir uma paisagem homogênea do conjunto de alunos, camuflando eventuais preferências pessoais, $e$ de sinalizar o pertencimento a um grupo à parte. Esse uso dos uniformes evidenciou-se na pesquisa quando estas fotografias foram comparadas com retratos de turmas de alunos de escolas, públicas ou privadas, que prescindiam dos uniformes. Visivelmente, o conjunto desses alunos mostra-se muito mais heterogêneo socialmente. Nas escolas confessionais femininas, a forma pela qual os uniformes surgiram revelou-se plena de significados, mesmo quando comparada à maneira pela qual a vestimenta dos meninos era gerida nas escolas confessionais masculinas. No Colégio São Luís, para onde iam os filhos das mesmas famílias, os meninos aparecem na fotografia, em sua maioria, vestidos de paletó e gravata. Mas paletós, calças e gravatas possuíam modelos e cores distintas, evidenciando-se um controle muito mais discreto no uso do vestuário em comparação com sistema vigente nas escolas femininas. Em uma típica fotografia de turma do Colégio São Luís - no pátio do colégio, com os padres posicionados sentados nas laterais do retrato e os alunos enfileirados por tamanho - muitos meninos aparecem sem gravata, outros tantos com os primeiros botões da camisa abertos ou simplesmente dispensando o paletó para vestir um suéter. ${ }^{39}$ Diferentemente, nas escolas femininas o cuidado, o rigor $e$ a obsessão com os uniformes revelaram-se uma forma de inculcar nas meninas uma atenção especial com a aparência exterior do corpo. Por meio das solenidades escolares e dos rituais de

${ }^{39}$ Fonte: Anuário do Colégio São Luís. Publicação interna, São Paulo, 2000, p.22. 
Classe, gênero e corpo em uma escola para meninas

exposição das alunas, nas quais os uniformes desempenhavam um papel chave, a instituição escolar dava a sua contribuição específica para fazer da experiência feminina do corpo, um corpopara-o-outro. ${ }^{40}$

Uma análise do trabalho realizado pelo Des Oiseaux mostra que esse "corpo para o outro" pode assumir feições diferenciadas segundo a posição na estrutura social, revelando-se assim a sua dupla determinação social. A experiência educativa nesta escola garantia uma socialização precoce com uma cultura estética, revelada no ambiente escolar, nas cerimônias escolares, no momento das refeições e na gestão dos uniformes; uma educação cultural que funcionava, a rigor, como sinal de distinção social. Portar o uniforme do Des Oiseaux, por exemplo, propiciava às meninas uma socialização com o corpo de completa aprovação social. $^{41}$ Por meio deles as meninas experimentavam uma aproximação entre o corpo real e o corpo ideal, portanto, legítimo de ser apresentado. Esse encontro entre o corpo real e o corpo socialmente legítimo produz uma segurança em si e a certeza de poder controlar as normas de percepção e apreciação dos outros sobre o próprio corpo. ${ }^{42}$

${ }^{40}$ Cf. Bourdieu, P. A dominação masculina. Rio de Janeiro, Bertrand Brasil, 1999, p.79.

${ }^{41}$ A observação feita por uma ex-aluna de outra escola feminina revela como os outros, de fora desta escola, percebiam o colégio, "O sonho dourado da minha mãe era me ver com aquele uniforme do Des Oiseaux... era conhecido na cidade, as meninas saíam do colégio com aquelas fitas de cetim..." Fonte: Entrevista de pesquisa. Agosto, de 2002.

${ }^{42}$ Cf. Boudieu, P. Op. cit. 
Um retrato de classe

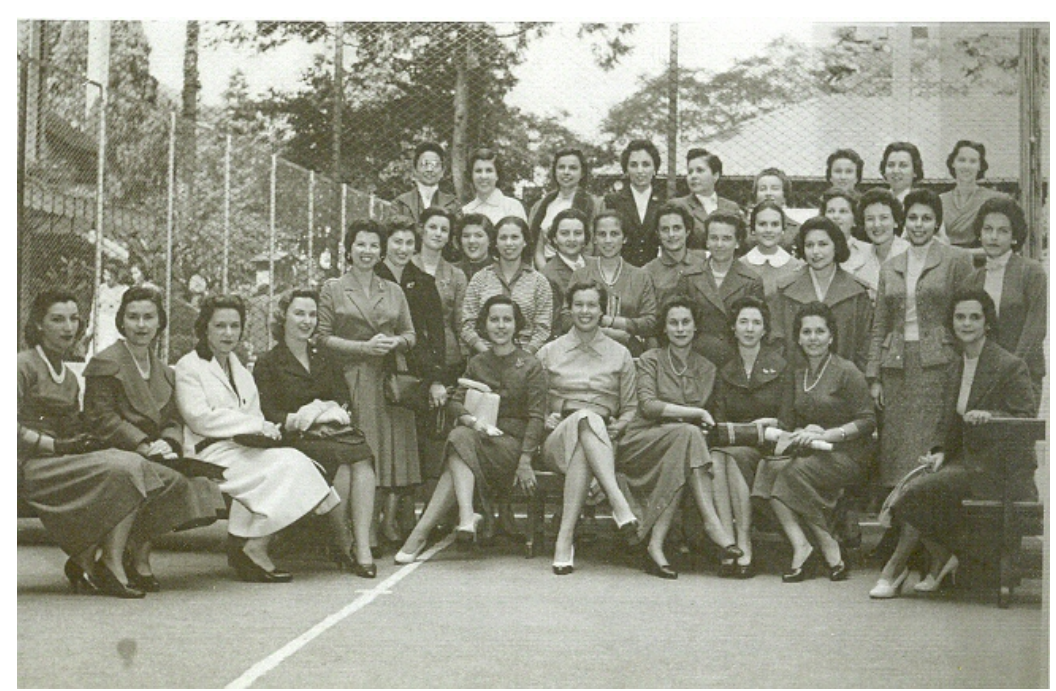

Fotografia 5: Ex-alunas do Colégio Des Oiseaux, reunidas em 1957 por ocasião da comemoração do ciquentenário do colégio.

Fonte: Arquivo pessoal de C.B.

Esta fotografia realizada em 1957, na quadra de tênis do clube "Harmonia", por ocasião da comemoração do cinqüentenário do colégio permite ao observador notar rapidamente que se trata de um grupo de "mulheres de classe", como se diz na linguagem ordinária. Vestidas com discretos tailleurs, elas possuíam entre 20 e 30 anos. Os detalhes emblemáticos dessa posição social podem ser reconhecidos nos escarpins, nos casacos, nas golas largas, nos colares, broches $e$ luvas. Mas eles não seriam suficientes para compor a impressão transmitida pela fotografia, não fosse, a héxis corporal do grupo. ${ }^{43}$

${ }^{43}$ Sobre a relação entre propriedades sociais e héxis corporal, consultar BOURDIEU, P. Remarques provisoires sur la perception sociale du corps. Actes de la recherche en sciences sociales, $\mathrm{n}^{\circ} 14,1977$, pp.51-54. 
Classe, gênero e corpo em uma escola para meninas

A maneira de sentar-se, de cruzar as pernas e acomodar as mãos fundadas no duplo pertencimento social, de classe e gênero. Essa imagem permite interrogar como se produz o efeito assustadoramente harmônico do grupo, sem que ninguém tenha orquestrado os gestos, os sorrisos e os olhares. O mistério do charme das "mulheres de classe", captado nas lentes do fotógrafo, é o resultado da transformação de propriedades sociais em "essência natural" - a elegância, a beleza, a confiança em si próprio, que o grupo fotografado exprime tão bem. Isso se torna possível, porque o grupo estava em condições de fazer todos os investimentos que custam tempo, energia e dinheiro para modificar os corpos, aproximando o corpo real do corpo ideal $e$ por isso, legítimo de ser apresentado. E estavam em condições de controlar àqueles que produzem os retratos do grupo (fotógrafos, pintores, biógrafos, jornalistas, etc.), prefigurando sua própria imagem por meio de um trabalho de representação que inclui uma certa teatralização, uma esteticização da pessoa e da conduta, que visa a rigor manifestar sua condição social. Essa natureza cultivada, posta nos corpos, exprime uma determinada relação com o mundo social, dada pela posição privilegiada na estrutura social e pela separação entre homens e mulheres no domínio econômico neste grupo social e no período em questão.

A análise do trabalho desenvolvido por esta escola "para meninas de classe" mostra claramente de que maneira as mulheres deveriam contribuir para a construção desta classe social $e$ de que maneira o gênero desempenha um papel central na constituição dos grupos sociais. ${ }^{44}$ Como colaboradoras das carreiras masculinas, favorecendo-a pelas redes de parentesco $e$ amizade, elas atuavam enobrecendo a atividade econômica do marido, acrescentando uma dimensão estética ao sucesso profissional dele, possível graças a uma formação escolar $e$ familiar. Nesse espaço de educação escolar, os menores rituais do

${ }^{44}$ Cf. FREVERT, Uti. Classe et genre dans la bourgeoisie allemande du XIX siécle. Genéses, n 6, 1991, pp.5-28. 
cotidiano, como as refeições ou a aula de história, davam lugar ao culto à tradição das grandes famílias.

Essa é a particularidade das escolas destinadas às famílias de alta renda - e o Des Oiseaux não é mais do que um caso limite - elas tendem a produzir os efeitos de uma educação total, endereçada à pessoa como um todo, provocando efeitos ainda mais profundos na medida em que reforçam os códigos, as maneiras de pensar e de ser, presentes no universo familiar. ${ }^{45}$ Com essa educação total, as escolas de elite exercem um papel ainda mais acentuado na diferenciação social de seus alunos e agem decisivamente na composição de horizontes possíveis. Considerando-se a militância histórica da Igreja Católica na elaboração de uma doutrina que fazia do casamento uma especialidade da teologia católica romana - cujos "cursos de noivos" são uma expressão - não surpreende o fato de que nenhuma das moças desta escola, no interior do grupo pesquisado, tenha abdicado ao casamento. E, em relação às alunas das demais escolas de elite pesquisadas, a separação conjugal entre elas foi menor, assim como foi menor o investimento em uma carreira profissional. Vê-se, dessa maneira, como a escola não pode ser desprezada como uma instância de socialização decisiva nos processos de diferenciação social, na medida em que contribuem para a interiorização de disposições psicológicas, morais e intelectuais específicas, sobre as quais se estruturam uma determinada maneira de se ver no mundo que orienta os investimentos no espaço de relações sociais.

${ }^{45}$ Cf. FAGUER, Jean-Pierre. Os efeitos de uma "educação total": Um colégio jesuíta, 1960. Educação e Sociedade 58, 1997, pp.9-53. 